\title{
When perception isn't reality: Accent identification and perceptual dialectology in French ${ }^{1}$
}

\author{
ZÖ̈ BOUGHTON
}

University of Exeter

(Received May 2006; revised June 2006)

ABSTRACT

This article examines levelling and diversity in northern urban French pronunciation through the optic of folk (= non-linguists') perceptions of variation. These perceptions are investigated by the identification of authentic voice samples (rather than other instruments widely used in perceptual dialectology such as mental mapping): respondents from the Pays de la Loire region of north-western France heard extracts of scripted speech from Nancy and Rennes, and were asked to identify the speakers' regional background and say whether they were of urban or rural origin. The results of this test show that while some difference between the two speaker location groups was accurately perceived, the informants also formed some inaccurate judgements, partly based on social stereotypes. Overall there is some confirmation of accent levelling, and of general social psychological tendencies such as stereotyping, annexation and time-lag in perceptions of regional-social linguistic variation.

\section{INTRODUCTION}

The domain of folk linguistic enquiry (Niedzielski and Preston, 200o) which has come to be known as perceptual (or folk) dialectology originated at least partly as a response to the failure of much social-psychological language attitudes research to pose questions of accent identification (Preston, I989: 3; I999b: 359); in other words, respondents' evaluations of speakers with certain accents were elicited without it being explicitly checked that they knew which accent was being represented, usually in a matched-guise test (cf. Boughton, 200I: 222). It could therefore be deemed somewhat strange that throughout the growth of perceptual dialectology since the I980s into the burgeoning sub-discipline it is today (witness the two weighty Handbooks published in 1999 and 2002), accent identification as an experimental task has remained on the methodological sidelines and has not

${ }^{1}$ I am grateful to the editors, readers and to Aidan Coveney for their helpful comments on drafts of this article. Naturally, I alone am responsible for any errors that remain. I am also greatly indebted to Nigel Armstrong and Marie-Anne Hintze for their involvement in the design of the Pays de la Loire perceptual study, as well as to the fieldworker, Tracy Agnew, and all of the subjects who kindly participated in the test. 
been as widely used or developed as other research tools, the most notable example being perceptual or mental mapping.

The latter technique, drawn from the work of cultural geographers such as Gould and White (I986), has now been used in many studies on numerous languages around the world. It allows researchers to tap into folk (= non-specialist) knowledge about areal variation in language by giving informants a (more or less) blank map of a country or region and asking them to indicate on it where they believe varieties to differ, for example by drawing boundary lines or circles, and assigning labels to places thus demarcated. It is a kind of approach which fits broadly into the spirit of the ethnography of speaking in emphasising that 'the total context of communication and ideational structure behind communication events are as worth studying as linguistic performance data' (Preston, I989: 4). Since this is the general thrust of the folk linguistic enterprise, it is not surprising that perceptual mapping has been so widely used, since part of the reason for preferring this technique is that it elicits overt perceptions of (or beliefs about) variation as opposed to the covert reactions to voices obtained by matched-guise tests; it also obviates the need to use imitations of varieties which may be nearer to stereotypes than authentic usage.

Hence during the I980s, Preston developed several techniques for the study of folk linguistic knowledge of regional dialect variation (Preston, I999a: xxxiv): firstly, mental mapping, or 'draw-a-map', discussed above; secondly and thirdly, two ranking tasks: perceived 'degree of difference' of the dialect from the respondent's own, and then evaluation of the relative 'correctness' and 'pleasantness' of speech in a perceived area; fourthly, a 'dialect identification' task requiring informants to listen to voices of different degrees of dialect markedness and link them to places, and finally qualitative data may be elicited by asking open-ended questions about the above tasks, or about varieties, their speakers and similar metalinguistic topics. Of particular relevance here is the preference for mapping and rating tasks over identification, which is deliberately placed towards the end of the list of tools. This, Preston argues (I999b: 359, 368), is because it is desirable first to discover what mental constructs of regional variation respondents have before presenting them with voice samples; to do otherwise would be to risk asking them to identify or evaluate a variety which they had no prior conception of or knowledge about. He concedes (I999b: 369) that this amounts to an investigation of respondents' stereotyped internal representations of regional speech forms and that this is just one way of approaching broader questions of identification and evaluation, but cites supporting evidence of research in Wales showing that evaluations differ little if at all whether the stimulus is a voice sample or merely the name of a variety (Coupland, Williams and Garrett, I999; Williams, Garrett and Coupland, I999). However, the fact that this is the case for varieties of Welsh English does not necessarily mean that it will hold for other languages, such as French, and the whole question whether nonspecialists (or expert linguists, for that matter) can accurately identify accents and dialects is still relatively open (although cf. Williams, Garrett and Coupland, I999; Kerswill and Williams, 2002; Montgomery, 2005 for studies on British English, and various studies on French reviewed in Boughton, 200I, and below). 
So while the practice of drawing maps and evaluating dialects simply on the basis of labels for regional forms has the effect of eliciting overt perceptions of variation, such tasks do not straightforwardly address the identification conundrum. Yet in a recent perceptual dialectology study exploring Parisian and Provençal speakers' views of regional variation in French, Kuiper (2005) makes the bold claim that 'perception is reality'. In this article, I investigate and critique exactly what is meant here by the terms 'perception' and 'reality', for example by comparing earlier perceptual research (Kuiper, I999) with an accent identification experiment conducted in Rennes (Armstrong and Boughton, I998; Boughton, 200I; 2003). What emerges from this comparison is some evidence for a significant and interesting 'gap' between what native speakers believe about variation in French, and what they actually know about it when asked to judge authentic voice samples. Further insight into this matter, as well as some methodological considerations, will be provided by a brief review of other recent French accent identification studies.

The question of respondents' ability accurately to identify other native speakers' social and geographical origins on the basis of their speech is then pursued by the presentation and analysis of new data arising from a further accent identification experiment recently conducted in north-western France. The method used in the elicitation of this new data differs considerably from the test conducted earlier in Rennes, mentioned above. So in addition to analysis of the results, discussion will focus on a comparison of these two perceptual tests, on whether the results of the earlier test are confirmed or undermined, and on the relative merits of the different methods adopted. Finally, the results allow us to propose responses to the following questions: what do we learn about the ability of French native speakers to perceive and identify others' accents, and about attitudes to and perceptions of variation in French? Moreover, what do the results suggest about the extent of levelling in northern urban spoken French? They may provide further evidence of a 'gap' between folk beliefs about the extent of accent variation in France, and what is actually the case at the beginning of the twenty-first century.

\section{BACKGROUND}

\subsection{The Rennes perceptual study}

The perceptual study to be presented in section 3 was designed initially as an extension to an earlier piece of experimental research conducted by the present author in Rennes, Brittany in 1997 and I998. Since this has been described in detail elsewhere (Armstrong and Boughton, I998; Boughton, 200I; 2003), it will be reviewed only briefly here in order to contextualise the more recent work which grew out of it and which is the primary focus of this article.

The Rennes perceptual test was carried out as part of a wider variationist study examining the extent of phonological uniformisation in non-peripheral northern (or oil) urban French (Boughton, 2003). A large corpus of spoken French was gathered from stratified samples of speakers in Nancy and Rennes (hence the 
Table I. Size and structure of speaker samples in Nancy and Rennes

\begin{tabular}{llllll}
\hline \hline & \multicolumn{2}{c}{ MALE } & & \multicolumn{2}{c}{ FEMALE } \\
\cline { 2 - 3 } \cline { 5 - 6 } AGE & WC & MC & & WC & MC \\
\hline I6-25 & 4 YWM & 4 YMM & & 4 YWF & 4 YMF \\
$40-60$ & 4 OWM & 4 OMM & & 4 OWF & 4 OMF \\
\hline \hline
\end{tabular}

Key: YWM = Younger Working-Class Male, OMF = Older Middle-Class Female, etc., where $\mathrm{W}=$ manual/blue-collar and $\mathrm{M}=$ non-manual/white-collar.

'Nancy-Rennes corpus'), two medium-sized cities readily comparable with regard to their geographical, demographic and linguistic characteristics: they are almost equidistant from Paris, Nancy to the east, Rennes to the west, have populations of similar sizes and structures, share historically and culturally significant profiles within their regions and are both located in oil substrate dialect areas (lorrain roman and gallo respectively). The fieldwork method was designed to be identical in both locations, and was adhered to as consistently as possible. Semi-structured interviews of the type pioneered by Labov in the I960s (1972; cf. Milroy and Gordon, 2003: 57-68) were conducted in order to elicit and record both spontaneous and scripted speech, usually from a single informant. The size and social stratification of the two samples of 32 speakers (64 speakers in total) is shown in Table I.

The chief purpose of these urban dialect surveys was to gather data on which quantitative analysis of selected pronunciation features could be carried out in order to determine the extent of standardisation in two similar but geographically distant locations (Nancy and Rennes are approximately 700 kilometres or 440 miles apart). However, on completion of the fieldwork in Nancy, it seemed apt to put the impressions of the non-native fieldworker concerning the (lack of) markedness of a localised accent to the test by asking a panel of native French speakers to judge sample extracts of Nancy speech. This was done in Rennes by adding a listening 'test' to the end of the scheduled interviews. The forty Rennes informants, from which thirty-two were later selected to form the speaker sample for quantitative analysis and which was socially stratified as shown in Table I, were asked to listen to eight randomly-ordered one-minute extracts of spontaneous speech from Nancy interviews, each taken from a different cell of the sample, thus one YWM, one OMF, etc. After each extract, the Rennes respondents answered the following deliberately broadly framed questions:

A In your opinion, does the person speaking have an accent?

$\mathrm{B}$ Is the person more likely to be working-class or middle-class?

C Can you identify the person's region of origin?

D Do you find the person's accent pleasant?

Since this article is concerned above all with the matter of regional accent identification, the results of questions $\mathrm{A}$ and $\mathrm{C}$ are given in Figure I; questions B and $\mathrm{D}$ will not be revisited here (in summary, social class was generally accurately 


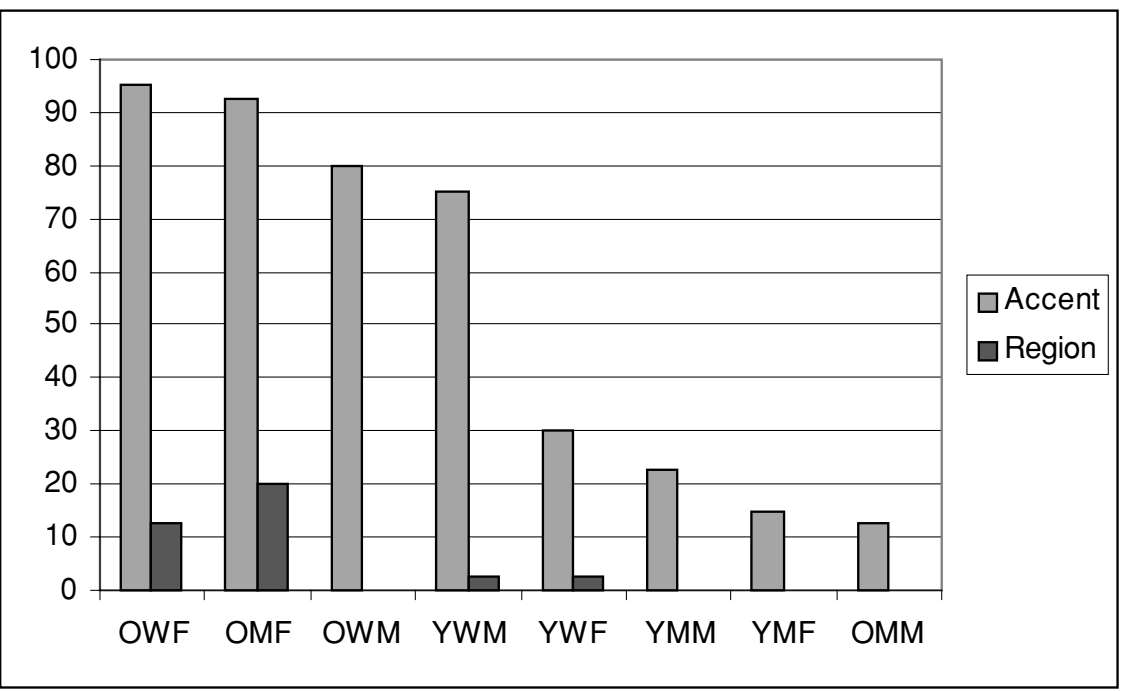

Figure I. Affirmative answers to question A ('yes, the person has an accent') and 'correct' regional identifications of the eight Nancy speakers.

identified, and there was an inverse correlation between perceived pleasantness and perceived markedness of accent).

Figure I shows in dark shading the percentages of 'correct' regional identifications of the eight Nancy speakers alongside affirmative responses to question A, 'in your opinion, does the person speaking have an accent?' The speakers are ranged along the horizontal axis in order of decreasing perceived markedness of accent from left to right (or 'accentedness' to 'standardness'). The obvious result shown here is that the Rennes respondents were for the most part unable to identify the regional origin of the Nancy speaker sample, more or less regardless of whether or not they perceived them to 'have an accent'.

It should however be noted that the term 'accent' in question A was not uniformly interpreted by respondents to denote 'regional accent'; on the contrary, this aspect was only infrequently mentioned when they chose to elaborate on their answer, their comments referring at least as often to other extra-linguistic variables such as socio-economic status, age, or urban as opposed to rural origin. Furthermore, some informants remarked on features other than pronunciation, such as syntactic and lexical features, as well as voice quality, revealing the rather flexible interpretation of 'accent' by these non-specialists. Nevertheless, Figure I shows a broad positive correlation between perceived markedness of accent (however interpreted) and social class of speaker: those perceived to have a marked accent, positioned towards the left of the chart, are predominantly working class, while those not so perceived, to the right, are middle-class. (The placement of the OMF speaker appears anomalous, but can be explained by the fact that her family 
background was working-class, and she had never left the quartier in which she was born and brought up.)

It is also clear that for most of the eight speakers, the proportion of 'correct' regional identifications hovers around zero, even though this was generously interpreted: any mention of eastern France in a response was categorised as accurate, even if the same respondent also guessed at Quebec, Paris, or Rennes itself, for example. By far the most common answer to question $\mathrm{C}$ was 'don't know' or 'no idea', which accounted on average for approximately $6 \mathrm{I} \%$ of all responses. The OMF speaker again stands out as having the highest correct identification score (though this is still only 20\%); this is due to her still occasionally signalling her working-class and local origins by certain non-standard accent features, one of which, an apparently salient and diagnostic shift of stress to the penultimate syllable

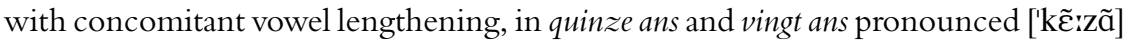
and ['vש̃:tã], featured prominently in the chosen extract, even though it occurred only once in the one-minute speech sample, after approximately 45 seconds of talk had elapsed.

Successful identification of an accent will of course depend on several factors in addition to straightforward sensitivity to linguistic differences, including the life experience and 'sociolinguistic maturity' of the respondents, the perceived social attractiveness of the speaker resulting from paralinguistic aspects of the speech extract, such as content, voice quality and tempo, and also the actual linguistic features present and how 'salient' they are (Trudgill, I986: I I), or, in the terms of Preston's (I996; I999b: 360) 'modes of folk linguistic awareness', their 'availability' to be perceived and commented on, and the 'accuracy' and 'detail' with which judges are able to represent and characterise them (Kerswill and Williams, 2002: I75-6).

One interpretation of the more or less unqualified failure of the Rennes respondents to identify the regional origin of the Nancy speakers is that it provides partial confirmation of the present author's observations of the relative standardness of the Nancy accent; in other words, few distinctive localised pronunciation features were present in the stimuli because they are not present in the variety in general. An alternative view is that even when informants did notice localised non-standard features, and some were indeed present, as mentioned above, they simply did not have the knowledge to allow them to assign them accurately to an area of France (the features were not 'available' to them). This is probably true to an extent, though as already noted, 'regionality' was not often mentioned in response to any of the speech samples presented; rather, the qualitative comments fall into the broad categories of 'standard'/ 'just like here' and 'non-standard'/'different from here'. Preston (I999a: xxxv) notes a related trend that emerges from qualitative data produced by a number of perceptual dialectology studies: 'overt identification of details of other varieties is very weak (perhaps particularly at phonological levels)'.

All the above considerations suggest a general lack of awareness among the Rennes respondent group of distinctive localised pronunciation traits in the voice samples, and perhaps of (northern) French regional accent features per se. This is even less surprising if the most marked features are in fact disappearing due 
to overarching processes of standardisation and levelling. Yet this seeming lack of awareness stands in stark contrast to results obtained by Kuiper (1999) in a 'classical' perceptual dialectology study which used the 'mainstream' mapping and rating methods to tap into Parisian respondents' perceptions of regional French. His seventy-six informants were given a map of France which was blank except for certain cities, rivers and mountain ranges, and asked to "circle and identify in writing any regions "where people have a particular way of speaking" (Kuiper, 1999: 244). A composite map produced from these responses shows that Alsace-Lorraine was the second most frequently designated area ( $55 / 76$ or $72 \%$ of responses); in this it was preceded only by Provence $(63 / 76)$, and followed by the Nord/Lille $(44 / 76)$. The informants were then given a list of twenty-four regional varieties of French (Belgian and Swiss included though they are non-metropolitan) and asked to rate them according to degree of difference from the norm (that is, the respondents' own variety), correctness and pleasantness. Lorraine French rates very highly (or badly) for markedness on all three rankings: 20 th out of 24 for degree of difference (where 24 th is maximally different), 2 Ist for correctness and 22nd for pleasantness. The regions usually ranked as more marked are Alsace, Suisse romande and Belgium. For Kuiper's Parisians therefore, Lorraine French sits at the bottom of the perceptual heap, as they believe it to be strongly divergent from the norm, incorrect and unpleasant. But what the Rennes test results show is that when a different method is adopted, namely when judges are presented with authentic samples of Lorraine French (albeit urban, Romance-substrate Lorraine French), they perceive very little divergence, and are largely unable to link it to a particular region when they do. Thus there appears to be a gap between these different kinds of perceptions, elicited using different experimental tools, as well as between different kinds of realities, a gap which will be discussed further below.

\subsection{Other accent identification studies}

We now summarise a selection of research on the identification of French accents by native speakers in order further to contextualise the results to be presented in section 3. This selective review will concentrate on two recent studies closely allied to the concerns of the present article: Castellotti and de Robillard (2003) and Woehrling and Boula de Mareuil (2006). Earlier work, such as Bauvois (I996) and Bauvois and Bulot (1998), and language attitudes research (notably Paltridge and Giles, I984), is left aside here (cf. Boughton, 200 I for an overview), as is work on non-metropolitan varieties (for example, Rispail and Moreau, 2004).

The aim of Castellotti and de Robillard (2003) was to elicit native speakers' representations of seven varieties of French, the researchers' hypothesis being that representations are socially constructed and therefore revelatory of developments in the sociolinguistic landscape. One hundred and thirty-five respondents, more than half of them students, were played spontaneous speech samples of the following varieties: solognot, midi de la France, parisien populaire, africain, banlieue, alsacien and standard, some taken from radio or TV interviews, others from Carton et al. (1983). 
A questionnaire designed to activate attitudinal stereotypes was used, and a further group of students was interviewed later on to gather more detailed qualitative data on aspects of the first set of questionnaire results. With regard to degree of intelligibility and the desirability of 'speaking like that', rurality was found to be highly stigmatised, though the midi was positively perceived, which might mean either that its image is not exclusively rural, or that rurality is only stigmatised when it is northern. Regional variation was not found to be an important factor, signalling a major change over time when compared with the observations of Gueunier et al. (I978: 89) that regionality is the key element distinguishing 'good' and 'bad' speech. Detailed results are then given for the following questions: 'est-ce qu'un professeur/un présentateur du journal TV de 20 h peut parler de cette façon?’ (p. 227). The accents were ranked in the same order for both (namely standard, midi, parisien populaire, africain, alsacien, banlieue, solognot), but far fewer respondents considered the non-standard accents appropriate for a newsreader (associated with an idealised norm) than for a teacher (modelling an attainable, empirical norm). It is of note that the accents thought least appropriate for either profession were banlieue and, bringing up the rear by a considerable margin, solognot, illustrating the powerful stigmatisation of both the 'extreme urban' and the 'extreme rural'. Overall, the findings suggest that perceptions are organised with regard to two main axes, plus/minus rural and plus/minus socially marked.

Woehrling and Boula de Mareüil (2006) aimed to test the accuracy of identification of six varieties of French, and whether there is any interaction with speakers' geographical origin, age and speech style. The speech data were taken from corpora gathered under the auspices of the Phonologie du Français Contemporain (PFC) project $^{2}$ in Brécey (Normandy), Treize-vents (Vendée), the canton de Vaud (Suisse romande), Biarritz (Pays Basque), Douzens (Languedoc) and Marseille (Provence). Six speakers were chosen from each corpus to represent both sexes and varying ages and levels of education. In addition, for each speaker, two speech styles were included, a spontaneous Interview Style and a scripted Reading Passage Style. Two styles for each of six speakers from six different regions gives a total of seventy-two short stimuli (average length just 8.84 seconds). A fairly homogeneous panel of twenty-five listeners from the Paris area each listened on computer to the extracts presented in a random order, clicking on one of six buttons after each sample to indicate perceived region of origin.

The results show that all six regional origins were recognised at rates significantly better than statistical chance: the overall success rate was $42.1 \%$ correct responses (chance being I/6 or $17 \%$ ). But this indicator of apparent success hides a more complex and confused picture. While the Suisse romande stands out as by far the best identified area ( $7 \mathrm{I} \%$ correct identifications), the two northern regions (Normandy, Vendée) were often mistaken for each other, though not for the South or East. Their success scores of $50.7 \%$ and $37 \%$ respectively therefore reflect what amounted to a $50 / 50$ choice of northern accents, and similarly, correct identification

\footnotetext{
${ }^{2}$ See http://www.projet-pfc.net/, accessed April 2006.
} 
rates of $36 \%$ for Pays Basque, $29.3 \%$ for Languedoc and $28.7 \%$ for Provence reveal a three-way choice between the southern accents, which were only rarely taken for northern and hardly at all for eastern.

The key finding that arises both from these percentage scores and from the application of techniques of cluster analysis and multidimensional scaling is a tripartition of perceptions of the accents studied according to East (Suisse romande), North and South. The effect of speech style, scripted or spontaneous, was not found to be significant, whereas age was; the regional origin of older speakers was more likely to be correctly identified than that of younger speakers. (This result is in line with Carton et al.'s (1983: 93) uncontroversial statement that degree of accent standardisation ranges along a social continuum whose poles are older/rural/défavorisé/non-mobile (and male?) on the one hand and younger/ urban/favorisé/mobile (and female?) on the other.) While the authors concede that their conclusions are of a preliminary nature, and that different results might be obtained with longer stimuli or panels of judges from southern locations, the three-way grouping of the six accents into three broader geographical areas remains impressively robust.

\section{The pAys De LA LOIRE PERCEPTUAL STUdy}

\subsection{Motivation, aims and hypothesis}

As stated above in section 2.I, the perceptual study reported here was initially motivated by a desire to expand and build on the ad hoc experiment conducted earlier in Rennes. A particular aim was to address aspects of the method of that test which might be seen as limitations (cf. Boughton, 200I), in particular: (i) the relatively small number of speakers presented for evaluation (though cf. Castellotti and de Robillard, 2003, who used seven evaluation stimuli); (ii) differences of content in the extracts which could sway judgements and distract listeners from pronunciation features alone; and (iii) the seemingly uneven framing of questions B and C: B, 'is the person more likely to be working-class or middle-class?', appears to offer a $50 \%$ chance of correct social-class identification, while C, 'can you identify the person's region of origin?', is more open and does not give the respondent any guidance as to what might be a correct answer. The principal hypothesis of this study, however, remains the same: that owing to the levelling of regionally marked pronunciation features, native speakers will find it difficult to identify accurately the geographical origins of speech samples of urban oil varieties. Other factors to be tested, such as the effect of inclusion of two different varieties (both Rennes and Nancy) in the stimuli, have to do with the methodology adopted, to be described next.

\subsection{Method}

The fieldwork was carried out firstly in La Baule (Loire Atlantique département) in 2002 to 2003, where the field researcher (Tracy Agnew) had been appointed as an 
English language assistant in a school for her intercalary year in France, and then from 2003 to 2004 in the département of Maine-et-Loire, following the fieldworker's appointment to a further teaching post. The overall panel of informants numbers thirty-two, and is socially stratified - male and female, younger and older, working class and middle class - in the same way as the samples shown in Table I. (The effects of listener variables are not examined here, but the design of the informant sample allows them to form the object of a future study.) All thirty-two were originally from these two départements in the Pays de la Loire region, or had lived there for at least ten years; the present perceptual study is therefore referred to here by the name of this area of north-western France. The Loire Atlantique sub-sample consists of eight informants, most of whom were pupils or teachers at the school where the fieldworker was employed; they were either from La Baule itself or from nearby Guérande and St Nazaire, all towns on the Atlantic coast near the mouth of the Loire estuary, approximately 70 kilometres ( 45 miles) from the important urban centre of Nantes. However, it proved difficult to find informants 'native' to the area, especially ones who could be classified as working class (principally on the basis of (manual/non-manual) occupation and level of education; the vexed question of class categorisation will not be discussed further for reasons of concision), a problem not uncommon in sociolinguistic fieldwork in France (cf. Boughton, 2003: 40; Coveney, 2002: 5). The sampling of respondents was therefore pursued during the following year in the neighbouring département of Maine-et-Loire via personal contacts of the field researcher (the 'friend-of-a-friend' approach described by Milroy and Gordon, 2003: 32, 75) in the town of Beaufort-en-Vallée and the nearby city of Angers, both situated in the western end of the Loire valley, until twenty-four more informants had been found, socially stratified as described above, and filling the cells of the required 'quota sample' (Milroy and Gordon, 2003: 30) of thirty-two in total.

The fieldwork locations were thus determined chiefly by practical considerations, but there is also a theoretical interest in their relative proximity to Rennes (about I $30 \mathrm{~km} / 80$ miles) compared with their distance from Nancy (about $750 \mathrm{~km}$ / 470 miles): the inclusion of voice samples from both cities represented in the Nancy-Rennes speech corpus (rather than just Nancy as in the earlier Rennes study) in the perceptual test stimuli adds a further element to the hypothesis stated in 3.I above, namely that if respondents from the Pays de la Loire region are unable to distinguish between speakers from Nancy and Rennes, this would lend additional support to the view that (northern) French pronunciation is highly levelled. The perceptual stimulus tape was thus designed to test this aspect of the hypothesis: thirty-two extracts were included on it, with sixteen speakers from each of Rennes and Nancy, randomly ordered (Nancy OMM, Rennes YWF, Rennes YMM, Nancy OWM, etc.; the full list is given in the Appendix). It was decided that to include samples of all sixty-four interviews in the Nancy-Rennes corpus would prolong the test undesirably and risk increasing respondent fatigue, so two speakers from each cell of the Nancy and Rennes sub-corpora were selected, as shown in Table 2; in this way, the speaker sample is increased fourfold when compared with the earlier group of eight Nancy speakers used in the Rennes study. 
Table 2. The Nancy and Rennes speakers sampled on the Pays de la Loire perceptual test tape

\begin{tabular}{|c|c|c|c|c|c|c|c|c|}
\hline \multirow[b]{3}{*}{ AGE } & \multicolumn{4}{|c|}{ NANCY } & \multicolumn{4}{|c|}{ RENNES } \\
\hline & \multicolumn{2}{|c|}{ MALE } & \multicolumn{2}{|c|}{ FEMALE } & \multicolumn{2}{|c|}{ MALE } & \multicolumn{2}{|c|}{ FEMALE } \\
\hline & WC & $\mathrm{MC}$ & WC & $\mathrm{MC}$ & WC & $\mathrm{MC}$ & WC & MC \\
\hline I6-25 & 2 YWM & 2 YMM & 2 YWF & 2 YMF & 2 YWM & 2 YMM & 2 YWF & 2 YMF \\
\hline $40-60$ & 2 OWM & 2 OMM & 2 OWF & $2 \mathrm{OMF}$ & 2 OWM & $2 \mathrm{OMM}$ & 2 OWF & $2 \mathrm{OMF}$ \\
\hline
\end{tabular}

Key: YWM $=$ Younger Working-Class Male, OMF $=$ Older Middle-Class Female, etc., where $\mathrm{W}=$ manual/blue-collar and $\mathrm{M}=$ non-manual/white-collar.

Another difference from the Rennes perceptual study is the speech style sampled for identification and evaluation. It will be recalled that one potential limitation of the earlier study lay in the use of extracts of authentic spontaneous discourse taken from sections of interviews where speakers were fairly relaxed and producing relatively uninterrupted and fluent speech, which meant that the content and topic, considered to be of subsidiary importance, were not uniform and could have influenced the judges' perceptions in addition to the other linguistic and paralinguistic clues available to them. In the Pays de la Loire study, the extracts are therefore taken from a scripted rather than a spontaneous speech style, namely Reading Passage Style. This ensures uniformity of content, but does of course mean that speakers are likely to be monitoring their pronunciation more closely, possibly leading to the further attenuation of any localised features. The script of the selected extract is as follows:

Tout à l'heure, le jeune homme va prendre le train. Il part. Il ne sait guère ce qui l'attend. A la gare, sur le quai, des cantines, des sacs militaires, des valises sont entassées pêle-mêle. Il rêve à l'été dernier quand il ramassait les meules de foin. Le soleil baignait la campagne d'une lumière dorée, et çà et là, des bouquets de saules offraient une ombre au bétail.

This was taken from a reading passage entitled 'Devoir de $\mathrm{CM}_{2}$ ', used in Lille by Lefebvre (I991: 65) and adopted for the surveys in Nancy and Rennes (Boughton, 2003: 62) as it contains a good number of potential phonological variables, such as the realisation of the front and back rounded mid-vowels (as in heure pronounced $[œ \mathrm{R}]$ or $\left[\phi_{\mathrm{R}}\right]$, and saules, [sol] or [sol]). The time taken to read the 68 -word extract varies from I 6 seconds up to 40 seconds; the average time taken by the 32 speakers is 24.53 seconds. This is less than half the length of the extracts in the Rennes study, but still longer than the IO-IS seconds that Harms's (I96I) respondents found sufficient to allow them to identify the social status of fellow speakers of US English (cf. also Bauvois, I996 (20-second extracts); Woehrling and Boula de Mareüil, 2006 (nine-second extracts)). However, using stimuli longer than suggested necessary by previous studies may perhaps offset any potential disadvantages of scripted as 
Table 3. Rennes informants' perceptions of Nancy speakers most often judged to 'have an accent' as being of rural or urban origin

\begin{tabular}{llll}
\hline \hline $\begin{array}{l}\text { Nancy } \\
\text { speaker }\end{array}$ & $\begin{array}{l}\text { Perceived as } \\
\text { 'having an accent' }\end{array}$ & Perceived as rural & Perceived as urban \\
\hline OWF & $38 / 40$ & I I $/ 29$ & $6 / 29$ \\
OMF & $37 / 40$ & I5/34 & $2 / 34$ \\
OWM & $32 / 40$ & I5/3I & $2 / 3 \mathrm{I}$ \\
YWM & $30 / 40$ & I0/34 & $8 / 34$ \\
\hline \hline
\end{tabular}

opposed to spontaneous speech samples. Five-second gaps were inserted between each voice, so that the tape could be paused more easily, and its total length is approximately I 5.5 minutes.

The Pays de la Loire informants were asked to listen to the tape, one extract at a time, and to formulate their judgements by completing boxes in a grid, according to the information and questions given in the Appendix (the first part of the grid can also be found in the Appendix).

All these questions, except the first, are slightly different from those used in the Rennes perceptual study, listed in section 2.I. Though the wording of question I remains the same, there is an important difference in the information given to the informants: the protocol shows that they were told before starting to listen that the speakers come from the northern half of France, thus ruling out the south and other francophone areas such as Quebec and the Suisse romande (both of which featured as guesses at the origin of the Nancy speakers in the Rennes study). Moreover, ten medium to large northern cities were marked on the map as identification reference points, including both Nancy and Rennes, indicating to the respondents that these were possible places of origin. This contextual information was added to place a measure of constraint on the regional identifications, and to remove from the picture any suggestion of regions lying outside the northern half of metropolitan France.

Question 2 is new: it did not figure in the Rennes study, but was included in the Pays de la Loire test in order to investigate a rather unexpected finding to emerge from the earlier work, namely a correlation between the perception of certain Nancy speakers as 'having an accent' and as being of rural rather than urban origin, even though localised features were not correctly associated with the Lorraine region, or even with eastern France for the most part.

Table 3 shows rural and urban perceptions of the four Nancy speakers who are grouped on the left in Figure I owing to their being perceived by a majority of Rennes informants as 'having an accent' (it is not shown here, but the same four speakers were also those most frequently judged to be working class). The first column of figures gives the raw numbers of respondents answering question A affirmatively, shown as percentages in Figure I. The right-hand columns show the number of times rural or urban origin was mentioned whenever informants chose to elaborate on their response to question A; the denominators are not the 
same because not all made comments in every case. To take an example, 38/40 or $95 \%$ of Rennes informants thought the OWF speaker had an accent and of the twenty-nine who then explained their response, eleven associated her accent with a rural background, and six with an urban one. It is clear that for the three older speakers, accentedness is more often perceived as linked to rurality; this is less clear for the YWM, of whom there were more perceptions of an urban background, and more specifically of the banlieue (cf. Armstrong, 200I: 5I ff.). This perceptual connection between 'marked' and rural accents for older speakers, and between 'marked' accents and the banliene for younger speakers, will be revisited with regard to the results presented below.

A further difference from the Rennes study is in the framing of question 3, which is more open in the present study and also makes reference to the catégories socioprofessionnelles instead of the working class/middle class bipartition which may be conceptually alien to French informants (see Pooley, 2000: I26, I28-9 for a related discussion). In fact, although question B of the Rennes study appears to constrain responses to just two categories, the informants frequently replied using other terms, such as moyenne plus, milieu très aisé/élevé/cultivé, milieu paysan/ agricole/populaire/pas très aisé/ouvrière, pas beaucoup d'études, voix de serveuse (cf. Boughton, 200I: 236), which were then categorised as either working or middle class later, at the analysis stage. Similarly, the Pays de la Loire respondents offered a wide variety of labels in answer to question 3 . These will require careful consideration with regard to analysis, along with close attention to French conceptions of class, occupation and education. The responses to question 3 are therefore left aside here for future study, as are the qualitative data elicited by question 4. Again, the final question was designed to appear more open than that used in the Rennes study (D), and more examples (than just agréable) of possible evaluative responses are given in the protocol to guide the informants as to the type of judgements sought. The answers to this question are varied and complex; it may be possible to group them according to the status and solidarity axes that have emerged from numerous language attitudes studies, but they require detailed examination and will not be discussed further here.

\subsection{Results and discussion}

In this section the responses to questions I and 2 of the Pays de la Loire perceptual study are presented. Questions 3 and 4 will be dealt with in a future study. The first two questions are anyway more closely allied to the theme of the present volume, namely accent levelling and regional diversity in French, so the focus here will be on the regional identification of the speaker sample, and the related perceptions of urban or rural origin.

After hearing each voice sample, the Pays de la Loire respondents were first asked whether they could identify the regional origin of the speaker (question I). Different types of answers were noted in the grid by the informants: twelve of them gave only names of cities taken from the ten points de repère provided in the 
protocol; just three answered the question literally, naming only regions (e.g. ouest, est, centre, Bretagne, Normandie) and not mentioning cities at all, but the majority, seventeen out of thirty-two or $53 \%$ of respondents, wrote down a mixture of labels, referring both to specific cities and wider regions. In view of this divergence of practice, it was necessary to categorise the answers to question I to aid analysis and presentation of the results. Six categories were decided on:

- North (including responses of Lille, Rouen, Normandie, Picardie);

- East (including Nancy, Strasbourg, Dijon);

- West (encompassing Brest, Nantes, Rennes, Angers/Anjou, Loire Atlantique, Maine-et-Loire, Sarthe, Chartres, Pays de la Loire and normal(e) (since it was assumed that the latter term meant that the informant detected no difference from their own (Pays de la Loire) speech);

- Centre (including Tours);

- Paris (and région parisienne);

- 'Don't know' (indicated by a question mark or blank space in the grid).

Certain of the above categorisations, like the divide between West and Centre, are clearly debatable, but others emerged from the data itself, such as the distinction between Centre and Paris, the latter appearing to be a 'special case' and so constituting a category of its own. These divisions were nevertheless used consistently for the purpose of quantitative analysis of the data. A further point to note is that where informants gave more than one answer, for example 'centre ou ouest', both were counted separately; this means that the overall number of responses varies, which is why percentages rather than $\mathrm{x} / 32$ proportions are shown in Figures 2 to 9 below.

Figures 2 and 3 show the proportions, expressed as percentages, of identifications of the regional origins of the speakers which fall into the six categories listed above. It will be recalled that the speakers were sampled on the tape in a random order (see Appendix), but for presentation of the results they have been divided into two location groups, Nancy (Figure 2) and Rennes (Figure 3). This is preferable to displaying the results for all thirty-two speakers on a single graph, and also makes easier a comparison of the regional perceptions of the two groups. The speakers within each group have been presented in the same order from left to right on the horizontal axis; this ordering reflects two working hypotheses. Firstly, representatives of the same cell (e.g. Nancy older working-class males, numbered I and 2) are paired side by side on the assumption that they will be perceived in a similar way, and secondly, placement of cells from left to right indicates assumed increasing standardness of accent. In other words, since class is expected to be the most influential factor affecting both actual and perceived divergence in pronunciation, the working-class speakers are grouped to the left, and the middleclass speakers to the right. Within the class groups, males are on the left (less standard) and females on the right (more standard), and within these gender groups, older speakers are shown to the left of younger speakers. This hypothesised ordering of speakers from least to most standard speech is based both on general findings 


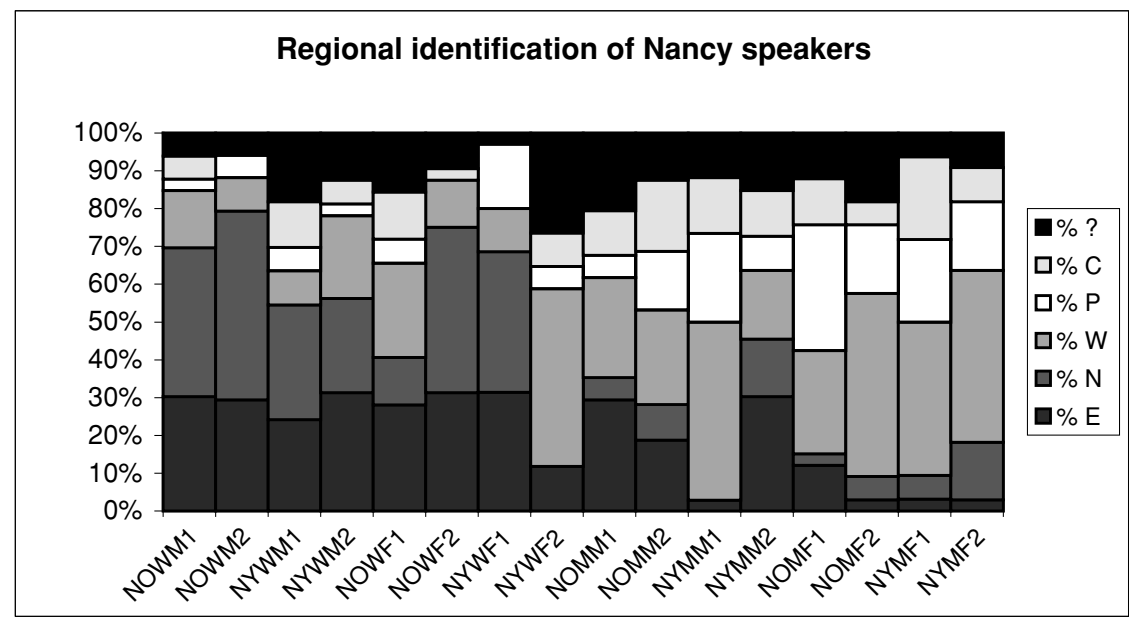

Figure 2. Regional identifications of the Nancy speakers by the Pays de la Loire respondents.

Key: NOWM = Nancy Older Working-Class Male, NYMF = Nancy Younger Middle-Class Female, etc.

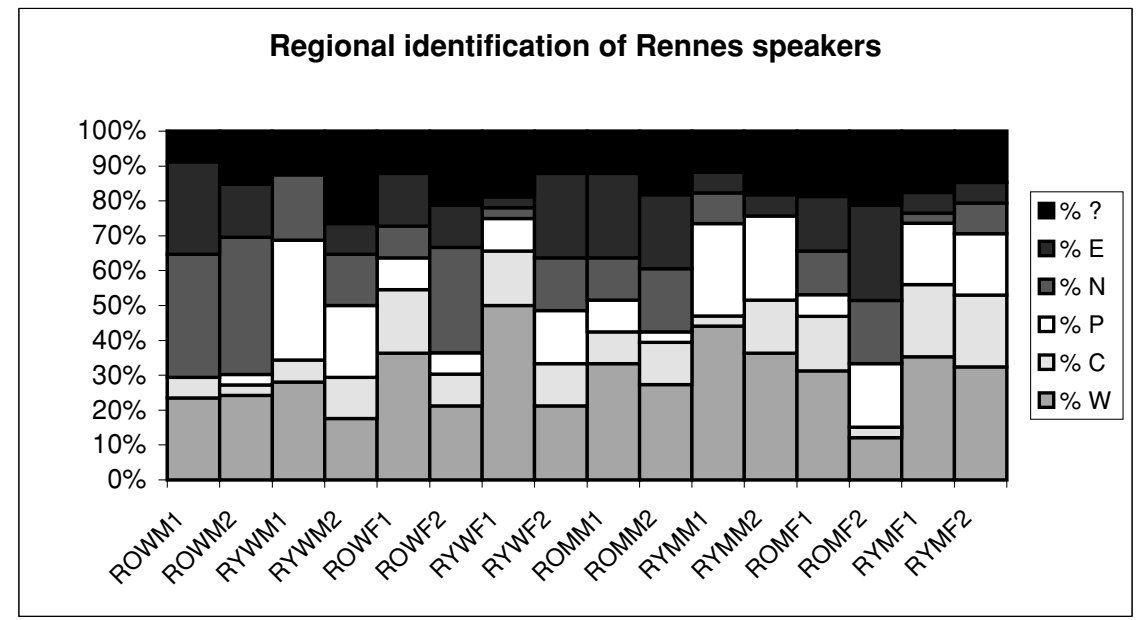

Figure 3. Regional identifications of the Rennes speakers by the Pays de la Loire respondents.

Key: ROWM $=$ Rennes Older Working-Class Male, RYMF $=$ Rennes Younger Middle-Class Female, etc.

of sociolinguistic research, and on the continuum implied by Carton et al. (1983: 93) referred to above. (The same order is used in Figures $2-5$, IO and II for ease of comparison.) However, it is important to note that the regional categories 
are presented in a different order from bottom to top on the vertical axes in Figures 2 and 3, for presentational and hypothetical reasons: the proportion of 'East' responses is shown at the bottom of the columns for the Nancy speakers to aid comparison across the location sample; similarly, 'West' is shown at the bottom of the columns for the Rennes speakers. 'North' is shown next for the Nancy speakers as this seemed to be the second most likely perception category; this is followed by 'West', 'Paris' and 'Centre'. For the Rennes speakers, 'Centre' and 'Paris' are shown above 'West', because it was assumed that these would be more likely perceptions than 'North' and 'East', shown in darker shading higher up. On both figures the proportion of 'Don't know' is shown at the top; no clear pattern is observed (Nancy average I 2.7\% '?', Rennes average I 6.2\%).

An examination of the 'East' responses for the Nancy speakers in Figure 2 shows that the proportion decreases from left to right, indicating a correlation between speaker's social class and perception as 'East'. Seven of the eight working-class speakers, seen on the left, are similarly perceived, each with around 30\% of 'East' responses. The second younger working-class female (i.e., NYWF2) seems to be a transitional speaker, patterning more obviously with the middle-class group; to the right of this speaker, the proportions of 'East' fluctuate, then stabilise close to zero on the far right-hand side. It is interesting to note that the transitional YWF speaker received the highest proportion of 'Don't know' responses and a considerable proportion of 'West' perceptions, indicating that she was difficult to place. Indeed, this speaker marks a second turning point in these results, as she is part of the (middle-class) group on the right showing a high proportion of perceptions as 'West', 'Paris' or 'Centre'. What appears here seems to be a further instance of the so-called annexationist tendency observed in a number of previous studies, whereby informants 'appropriate' speakers whose speech they perceive to be similar to their own (that is, they observe no salient divergence) as originating from the same region as themselves.

The overall average rate of 'successful' identifications of the Nancy speakers as 'East' is $20 \%$; compared with the earlier Rennes study average of $4.7 \%$, and this would appear to be a marked improvement, presumably resulting from the constraints added to the contextual information given in the protocol. However, with the responses grouped according to six categories, pure chance would result in an average of $17 \%$ (cf. Woehrling and Boula de Mareüil, 2006, cited above). What is perhaps of greater interest is the relation between social class and perception of 'East': the average 'East' score for the working-class Nancy speakers is $27.2 \%$ (29.4\% without NYWF2), but just I $2.8 \%$ for the middle-class speakers (the overall average masks this important difference). This contrasts with the perceptions of 'West': I $8.9 \%$ on average for the working-class speakers, increasing to $34.8 \%$ for the middle-class speakers from Nancy. A further point of note is that even though Nancy was named in the protocol as a point de repère, it was mentioned on average at a rate of just $4.2 \%$ of responses.

Figure 3 shows a different pattern of regional perceptions when compared with Figure 2, i.e. according to the actual geographical origin of the speaker samples. 
The overall average 'success rate' of perceptions of the Rennes speakers as 'West' is $29.7 \%$, somewhat higher than for the Nancy group (though the average score for mentions of 'Rennes' itself is just 4.3\%). This clearly shows that the northwestern Pays de la Loire informants were able to differentiate between the Rennes and Nancy speakers to some extent, but not straightforwardly; the greater overall proportion of accurate identifications of the Rennes speakers could be owing simply to annexation (implying that the accents of this group are less divergent generally; cf. Boughton, 2005 for some corroborative empirical evidence), and moreover, the proportions of responses in the other region categories reveal a complex picture. There is again some interaction between 'accurate' identification and social class, but it is in the converse direction to that observed for the Nancy speakers: the average 'West' score for the working-class speakers, on the left, is $27.8 \%$, while for the middle-class speakers it is $3 \mathrm{I} .5 \%$, so this modest upward trend is in the opposite direction than for the Nancy speaker group. The perceptions of 'East' are also in contrast with those observed for the Nancy speakers. The working-class Rennes speakers are perceived as 'East' at an average rate of I3.I\%, and the middle-class speakers at $\mathrm{I} 4 \%$, showing very little differentiation according to class. There is however a considerable class contrast with regard to perceptions as 'North': $20.7 \%$ on average for the working-class Rennes speakers, falling markedly to I0.2\% for the middle-class group. This perceptual gap between the Rennes class groups with regard to perception as 'North' will be explored further below.

Figures 4 and 5 illustrate further the complexity of the patterns shown in the regional identifications of the speaker samples, as well as interactions with social class of speaker and the nuances of social meaning that seem to exist between different regional labels. The lines on the graphs are cumulative so as to replicate part of the information shown in Figures 2 and 3 whilst highlighting more clearly some interesting gaps between the perception scores. An examination of the responses to question one, as discussed above, reveals the following inter-related trends: (i) the perception of 'West' increases from left to right along the hypothesised speaker axis of accent markedness to standardness; (ii) the perception of 'East' decreases from left to right for the Nancy speaker group; (iii) the perception of 'North' decreases from left to right for both speaker groups. Observations (ii) and (iii) suggest that 'North' and 'East' taken together constitute a major perceptual axis with connotations of non-standardness, and therefore association with working-class and/or less welleducated speakers. This non-standardness correlation can be clearly observed in Figure 4. However, a gap appears on the left hand side in the perceptions of the seven working-class Nancy speakers with similar levels of perception as 'East': we see here that the same seven speakers are much more likely than the others also to be perceived as 'North', and that the downward trend of the 'North plus East' line is much steeper, indicating that 'northern-ness' may function as an additional perceptual layer connoting lower social class in relation with 'eastern-ness' which may primarily imply divergence of pronunciation, also linked to social class for this group. The second major perceptual axis to appear is that allying standardness with 'West', 'Centre' and 'Paris', the other three regional categories. The correlation 


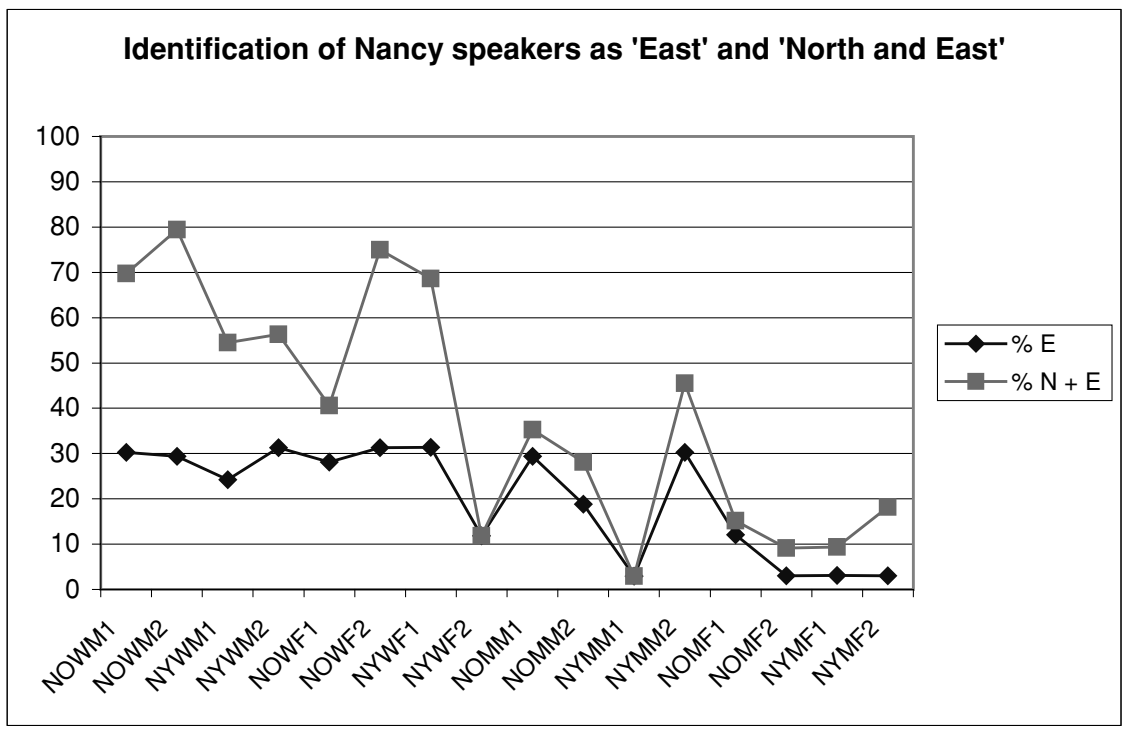

Figure 4. Identification of the Nancy speakers as 'East' compared with 'North' and 'East' taken together.

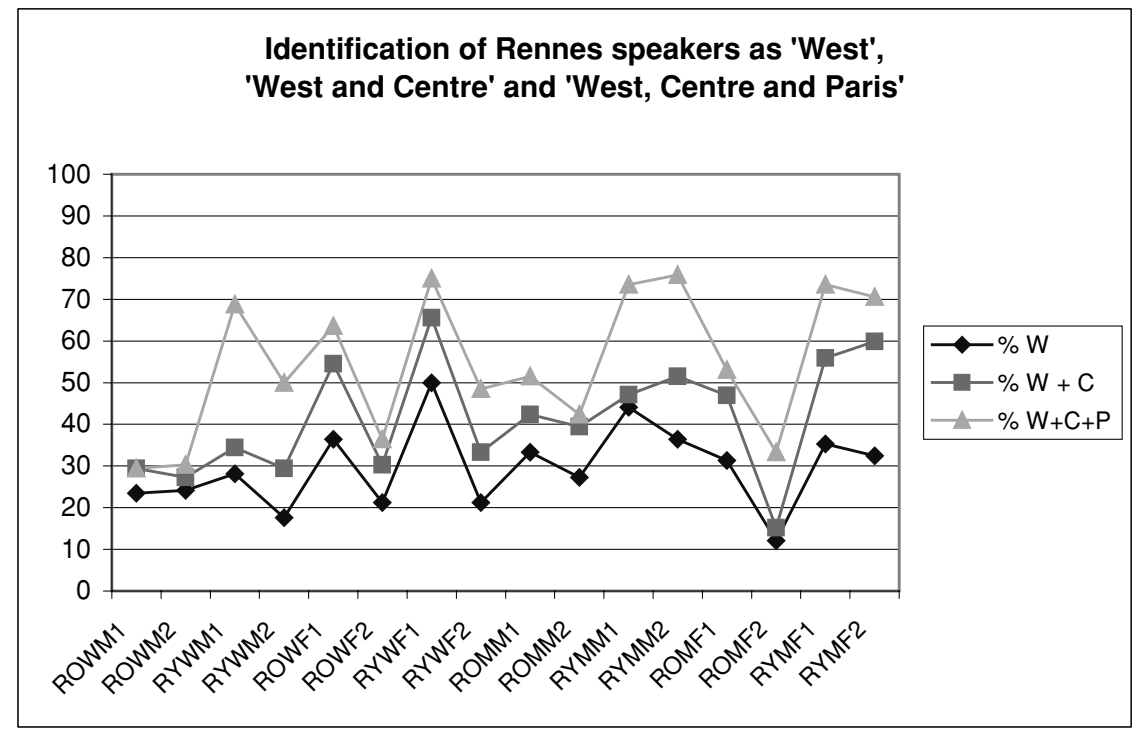

Figure 5. Identification of the Rennes speakers as 'West', compared with 'West' and 'Centre' taken together, and 'West', 'Centre' and 'Paris' taken together. 
between them is obvious in Figure 5: the cumulative score lines trace almost exactly the same patterns, with two notable exceptions: gaps appear for the Rennes YWMs and YMMs when 'Paris' is added to the equation. However, a closer look the data reveals that the connotations of 'Paris' are not the same for these two groups of younger males, and that there is again a class-based difference: responses indicate that for the YWMs, a 'Paris' answer is likely to mean banlieue parisienne, whereas for the YMMs, 'Paris' seems to connote standardness, presumably social and geographical (upward) mobility and possibly a fashionable 'media' accent; future analysis of the qualitative data elicited by question 4 may elucidate this. What is clear is that the label 'Paris' has a dual social meaning, and so for these younger Rennes males, accent difference is not associated with regionally-based divergence but with social differences.

Figures 6 to 9 again show the regional identification responses to question I, but this time using radar graphs: these offer perhaps the clearest visual presentation of the regional perceptions of the speaker groups because the four axes can be adjusted and labelled to reflect the traditional points of the compass. Within each radar 'web', a line represents a single speaker and joins the points on the axes which are plotted according to the percentage of a certain response (e.g., 'North') for that speaker. Here, the responses for 'Centre' and 'Paris' have been added together, especially as both seem on the whole to connote a lack of divergence (with exceptions, discussed above), in order to create four general perceptual 'directions'. The location groups are again separated and are further subdivided into class groups so as to highlight the contrasting perceptual patterns emerging from the results, both according to region and according to class of speaker. A comparison of Figures 6 and 7 (Nancy) with Figures 8 and 9 (Rennes) shows that while the patterns are similar, they are not identical, implying that the respondents were able to detect some broad differences between the location groups. Moreover, within the location groups, the class patterns are not the same. Figures 6 and 7 (Nancy) are almost mirror images of each other, highlighting a class difference which is clearer for Nancy than for Rennes. Figure 6 (working class) shows a bunching effect for 'East' and a strong pull towards 'North' that is not observed for the middle-class speakers (Figure 7); conversely, Figure 7 shows that the middle-class Nancy speakers are strongly associated with 'West', 'Centre' and 'Paris', less with 'East' and very little with 'North'. The 'North' axis most obviously separates the classes. The exception is again the 'transitional' YWF (NYWF2) whose line appears as an outlier in Figure 6, its shape much more similar to those shown in Figure 7. Figures 8 and 9 (Rennes) demonstrate that while there is again a global difference in the perceptions of the two class groups, the contrast between them is not as stark as for the Nancy class groups. Again, this may be due to the fact that the regional component of their accent, if there is one (cf. Boughton, 2005), is not as divergent as for the Nancy speakers and so does not serve as an additional perceptual clue differentiating the class groups. Both Rennes class groups show similar, albeit mixed, perceptions of 'East'; the middle-class radar shows a stronger pull and bunching towards 'West' and 'Centre'/'Paris', though several working-class speakers are similarly perceived, and 


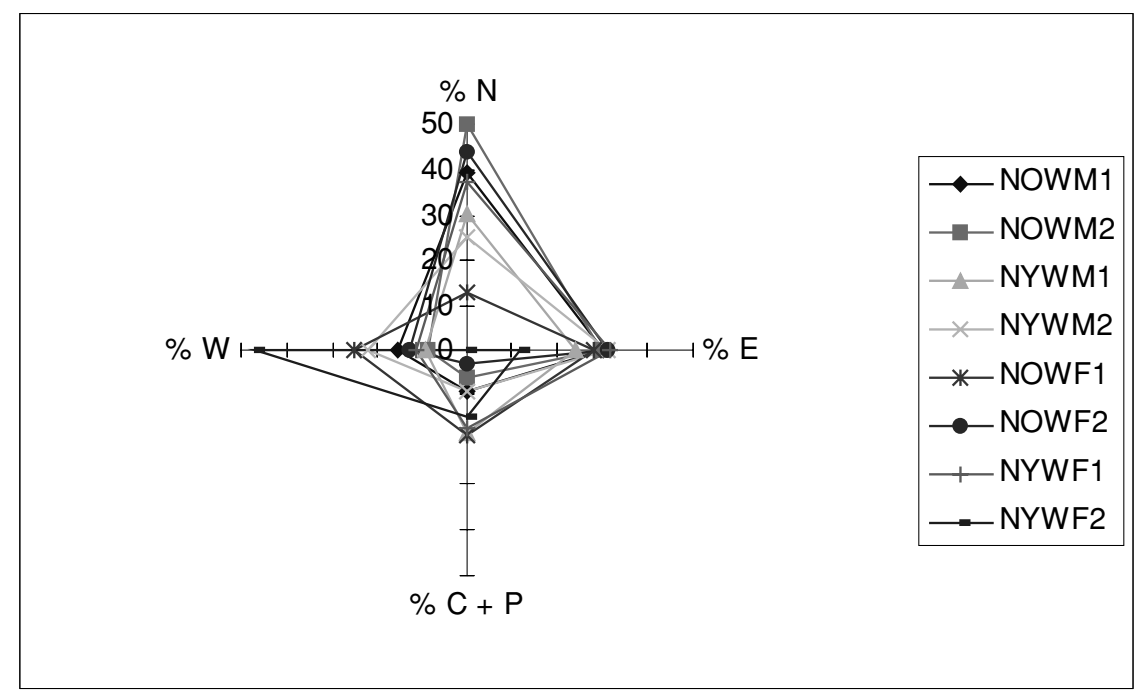

Figure 6. Radar graph showing regional identifications of Nancy working-class speakers.

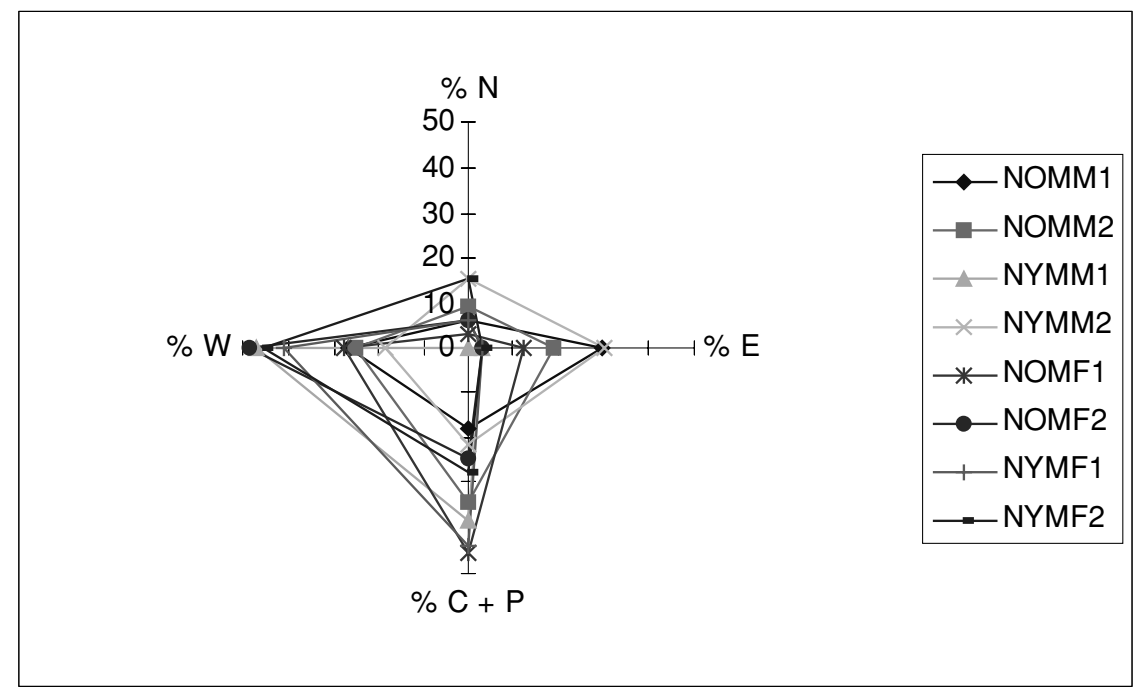

Figure 7. Radar graph showing regional identifications of Nancy middle-class speakers.

a comparison of Figures 7 and 9 shows that the Nancy middle-class speakers are in fact more strongly associated with the 'standard' axes of 'West' and 'Centre'/'Paris' than those from Rennes. What really separates the Rennes class groups is the strong association of the working-class speakers with 'North', and it will be recalled that 


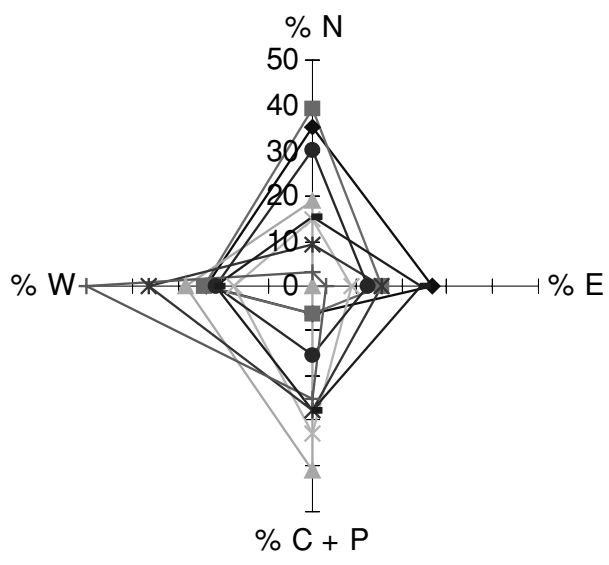

$\smile$ ROWM1

$\rightarrow$ ROWM2 RYWM1 RYWM2

$\rightarrow$ ROWF1

$\rightarrow$ ROWF2

— RYWF1 RYWF2

$\% \mathrm{C}+\mathrm{P}$

Figure 8. Radar graph showing regional identifications of Rennes working-class speakers.
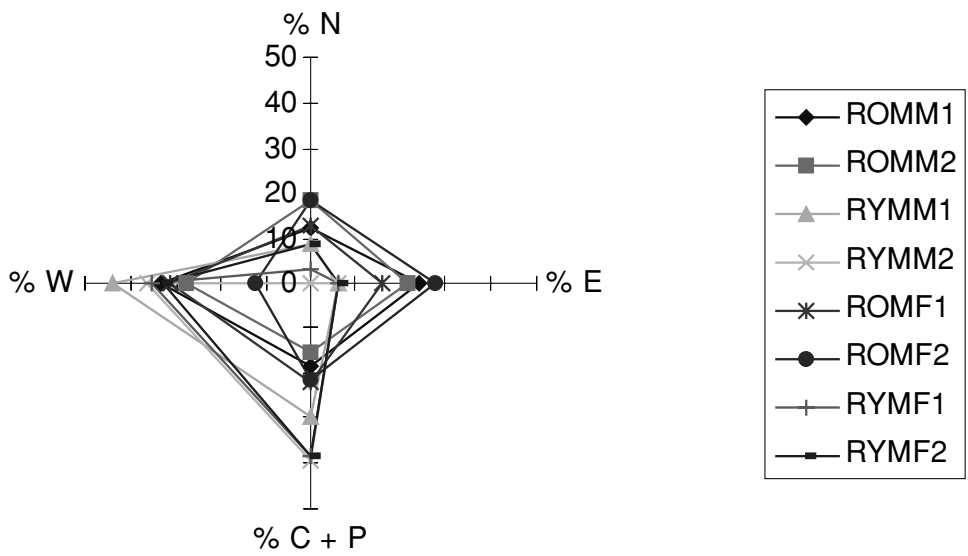

Figure 9. Radar graph showing regional identifications of Rennes middle-class speakers.

this category includes responses of Lille, Rouen, Normandie and Picardie - all a considerable distance from Rennes.

We turn now to a brief consideration of the responses to question 2, 'does this way of speaking evoke a particular city, or rather the country?' This question was designed to investigate further the result arising from the Rennes study, discussed 


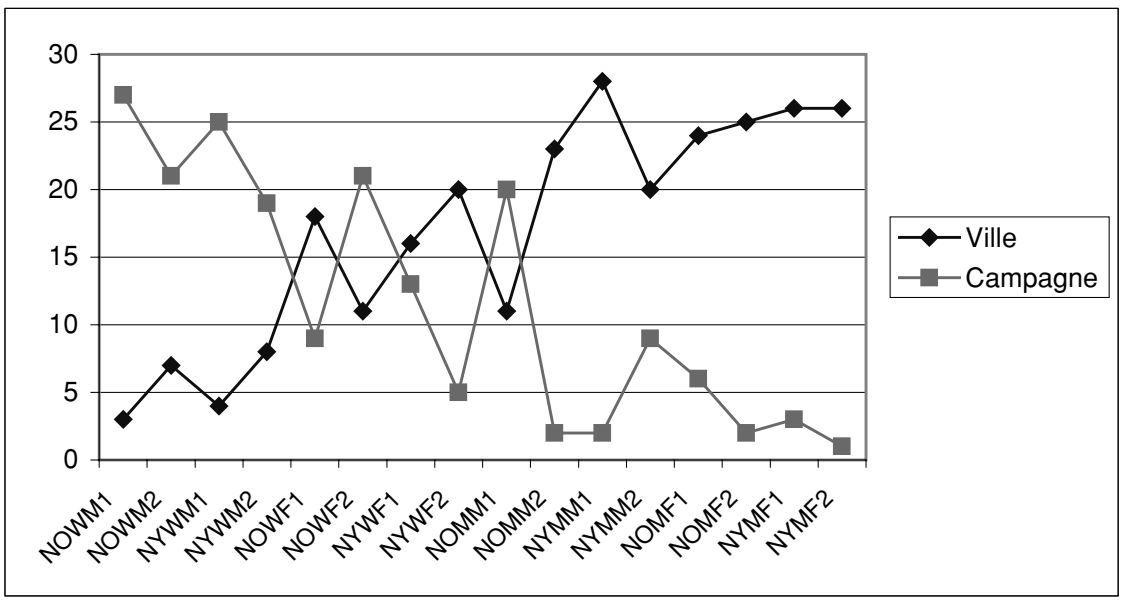

Figure Io. Pays de la Loire respondents' perceptions of Nancy speakers as being of urban or rural origin.

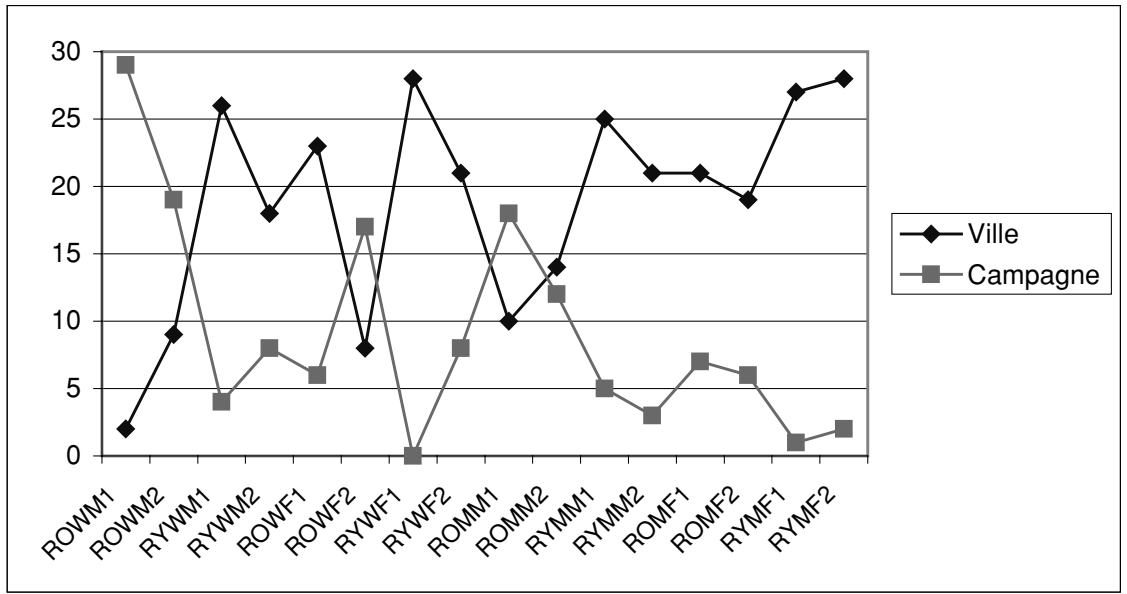

Figure I I. Pays de la Loire respondents' perceptions of Rennes speakers as being of urban or rural origin.

above, whereby speakers with 'marked' accents, especially older, working-class speakers, were perceived as being of rural rather than urban origin, when in fact they had all been born and brought up in the city (of Nancy). Figures Io and I I show the actual numbers, out of thirty-two, of responses of 'Ville' ('urban speech') and 'Campagne' ('rural speech'). No respondent gave more than one answer to this question, so raw figures rather than percentages are used. Four respondents gave some answers naming particular cities; in such cases they were categorised as 
'Ville'. Almost all the responses were simply either 'Ville', 'Campagne' or 'Don't know'. The results for 'Don't know' are not shown here, mainly for clarity's sake, but also because they represent a small proportion of responses (Nancy average 3.6/32, Rennes average 4.2/32); however, there is a very slight upward trend for both groups, i.e. from left to right on the speaker axis, possibly due to increased uncertainty of response the more standard the speaker's accent.

The responses of 'Ville' and 'Campagne' in Figures Io and I I show clearly that for both location groups, perceptions of rural and urban origin are in inverse correlation to the hypothesised speaker axis of marked to standard accents from left to right: working-class speakers, presumed to have less standard speech, are in general more likely to be perceived as rural than urban, whereas middle-class speakers, presumed to have more standard accents, are in general more likely to be perceived as urban than rural. The large gaps between the lines at the extremes of left and right demonstrate that this is most clearly the case at the poles of the proposed social continuum. A comparison of Figures Io and I I reveals that yet again there are differences in perceptions between the location groups, even though the overall trends are similar. The results for the Nancy speakers (Figure Io) are clearer than those for Rennes, insofar as the area of 'confusion' at the centre of the speaker continuum is less extensive. The YWFs again seem to mark a transition with regard to the overall trend, and just two speakers stand out as anomalous, the first OWF and the first OMM. There is no clear reason why NOMMI is more often perceived as rural than urban, though he is less well educated than NOMM2. NOWFI is unusual among the working-class speakers in that her occupation is manual supervisory; this may partially explain why she stands out from the group in being perceived more often as urban, and it is of note that with regard to regional identification, her 'West' score is relatively high at $25 \%$.

While Figure I I (Rennes speakers) reveals the same general trends as for the Nancy speakers, it is immediately apparent that the picture is a little more confused. The responses to the OWMs on the far left and the middle-class speakers to the right of ROMMi show the expected clear gaps between urban and rural perception, but there are six speakers in the centre of the graph who do not fall into line with the general tendency. This greater area of overlap than for Nancy may be a result of more guessed responses if it is indeed the case that the Rennes speech samples were in general less divergent, or it could be due to individual speaker characteristics. In the case of the YWMs, it is likely that the greater proportion of perceptions as urban than rural is linked to their being associated with the banlieue, as mentioned above; in other words, they are perceived to be urban, but this is not linked to standardness, and the hypothesised speaker order is not undermined here. The OMMs, on the other hand, are unexpectedly not perceived predominantly as urban; a related fact is that they were also more often perceived as 'North' and 'East' (36.3\% and 39.4\% respectively) than 'West' (33.3\% and $27.3 \%)$. The respondents clearly detected some non-standardness in their speech and there is no obvious explanation for this, except that there may be an effect of age and gender overriding that of class. The converse of this postulated age and gender effect is observed in the anomalous perceptions of 
the first OWF as urban rather than rural and of the two YWFs as overwhelmingly urban.

\section{CONCLUSION}

The foregoing results show that although the Pays de la Loire respondents were not especially successful at correctly identifying the regional origin of the samples, they were nevertheless able to detect some differences between the Nancy and Rennes speakers. For example, the average 'East' score for the Nancy speakers was $20 \%$, an improvement compared with the Rennes perceptual study, but the 'West' score for the same group was $26.9 \%$. This can be compared with an average of $29.7 \%$ 'West' for the Rennes speakers, whose 'East' score was I 3.6\%, so (correctly) lower than that for the Nancy group. Such differences in the regional perceptions of the two groups are quite impressive in view of the nature of the stimuli: 32 randomly-ordered 25 second identical scripted extracts, and this would seem to confirm the lack of effect of speech style observed by Woehrling and Boula de Mareüil (2006). However, even though the respondents were able correctly to identify some differences between the location groups, there is also clear evidence of annexation (cf. the Nancy 'West' score) when little or no divergence was perceived, mixed with reliance on stereotypes (e.g. 'North' equates to working class) when some accent difference was noted. Overall the results suggest two major regional-perceptual axes: 'North/East' connoting regional-social accent divergence and 'West/Centre/Paris' allied to convergence and standardness of accent. The urban-rural perceptions (cf. Castellotti and de Robillard, 2003) imply that while standardness is generally associated with urban origin, non-standardness is linked either with rurality when some regional (or social) difference is perceived, especially if the speaker is older, or with an urban background if social (but not regional) difference is perceived, especially if the speaker is younger. These results therefore reveal the binary social meaning of the 'urban' label which can connote both higher-class ville and lower-class banlieue.

Throughout the responses to the questions of regional and urban or rural origin, gaps emerge here and there between empirical realities (i.e. where speakers are actually from) and beliefs at least partially founded on social stereotypes. So to what extent can it be claimed that 'perception is reality'? Kuiper (2005: 28) states that folk perceptions may 'have little basis in empirical reality', but are nevertheless psychologically real and can therefore have a considerable impact on language attitudes, linguistic (in)security and perhaps therefore on linguistic behaviour. The elicitation of folk beliefs about regional variation is a fascinating and valuable research avenue in itself, but the use of authentic speech stimuli for identification and evaluation may not only reveal discrepancies between real and imagined degrees of divergence but could also serve to undermine potentially harmful stereotypes. Stereotypes about regional varieties surely exist in all speech communities, and France is no exception, despite the relatively advanced stage of standardisation of metropolitan French; perhaps the clearest ones identified in this study are that 'standard' means 'like me i.e. West/Centre/Paris' and 'socially marked' means 
'North', both beliefs that in many instances were far from the reality of the speaker's profile. This gap recalls other language 'myths' such as Hauchecorne and Ball's (I997) and von Nolcken's (2002; cf. Pooley, 2005) informants' beliefs in the existence of distinctive local accents, in Le Havre and a small Normandy village respectively, and Woehrling and Boula de Mareüil's (2006) respondents' confidence that they would easily recognise a Marseille accent, which did not prove to be the case. The Pays de la Loire perceptual study provides further evidence for a time-lag between (stereotyped) perceptions of variation in language and observable reality (cf. also Juillard et al., I994; Davies, I994), in this case the reality of increased homogenisation of pronunciation in a significant area of northern France. Indeed, many of the respondents simply did not believe it when they were told after the test that the speakers came from Nancy and Rennes, some of them needing to be persuaded for up to 30 minutes. As one informant put it, 'on ne peut pas résumer la personnalité, l'origine d'une personne avec la voix, juste avec son timbre de voix; peut-être il $y$ a cinquante ans mais plus maintenant' (emphasis added). From this point of view, some of the gaps between empirical and perceived realities that have been discussed here tell us something of where the language has been, but others, such as the differing perceptions of older and younger speakers, may hint at where it is heading in the future.

Author's address:

Zoë Boughton

French Department

University of Exeter

Queen's Building

The Queen's Drive

EXETER

$\mathrm{EX}_{4}{ }_{4} \mathrm{QH}$

e-mail: z.c.boughton@exeter.ac.uk

REFERENCES

Armstrong, N. (200I). Social and Stylistic Variation in Spoken French: A Comparative Approach. Amsterdam: John Benjamins.

Armstrong, N. and Boughton, Z. (I998). Identification and evaluation responses to a French accent: some results and issues of methodology. Revue PArole, 5/6: 27-60.

Bauvois, C. (1996). Parle-moi, et je te dirai peut-être d'où tu es. Revue de Phonétique Appliquée, I2 I: 291-309.

Bauvois, C. and Bulot, T. (1998). Le sens du territoire: L'identification géographique en sociolinguistique. Revue PArole, 5/6: 6I-79.

Boughton, Z. (200I). Methodological approaches to the study of French accent identification. In: M.-A. Hintze, T. Pooley and A. Judge (eds), French Accents: Phonological and Sociolinguistic Perspectives. London: AFLS/CILT, pp. 218-39.

Boughton, Z. (2003). Phonological variation in contemporary standard French: a tale of two cities. Unpublished $\mathrm{PhD}$ thesis, University of Newcastle upon Tyne. 


\section{Zö̈ Boughton}

Boughton, Z. (2005). Accent levelling and accent localisation in northern French: comparing Nancy and Rennes. Journal of French Language Studies, I 5: 235-56.

Carton, F., Rossi, M., Autesserre, D. and Léon, P. (I983). Les Accents des Français. Paris: Hachette.

Castellotti, V. and de Robillard, D. (2003). Des Français devant la variation: Quelques hypothèses. CILL, 29: 223-40.

Coupland, N., Williams, A. and Garrett, P. (I999). 'Welshness' and 'Englishness' as attitudinal dimensions of English language varieties in Wales. In: D. Preston (ed.), Handbook of Perceptual Dialectology, vol. I. Amsterdam: John Benjamins, pp. 333-43.

Coveney, A. (2002). Variability in Spoken French: A Sociolinguistic Study of Interrogation and Negation. Bristol: Elm Bank.

Davies, W. (1994). Dialect and standard in speakers' perceptions: delayed reactions to linguistic reality in a German city. In: M. Parry, W. Davies and R. Temple (eds), The Changing Voices of Europe. Cardiff: UWP/MHRA, pp. 295-309.

Gould, P. and White, R. (I986). (second edition) Mental Maps. Boston: Allen \& Unwin (cited in Preston, I999b).

Gueunier, N., Genouvrier, E. and Khomsi, A. (1978). Les Français devant la norme. Paris: Champion (cited in Castellotti and de Robillard, 2003).

Harms, L. (I96I). Listener judgements of status cues in speech. Quarterly Journal of Speech, 47: 164-68.

Hauchecorne, F. and Ball, R. (I997). L'accent du Havre: un exemple de mythe linguistique. Langage et Société, 82: 5-25.

Juillard, C., Moreau, M.-L., Ndao, P. and Thiam, N. (I994). Leur wolof dit-il qui ils sont? Langage et Société, 68: 35-62.

Kerswill, P. and Williams, A. (2002). Dialect recognition and speech community focusing in new and old towns: the effects of dialect levelling, demography and social networks. In: D. Long and D. Preston (eds), Handbook of Perceptual Dialectology, vol. 2. Amsterdam: John Benjamins, pp. I73-204.

Kuiper, L. (I999). Variation and the norm: Parisian perceptions of regional French. In: D. Preston (ed.), Handbook of Perceptual Dialectology, vol. I. Amsterdam: John Benjamins, pp. 243-62.

Kuiper, L. (2005). Perception is reality: Parisian and Provençal perceptions of regional varieties of French. Journal of Sociolinguistics, 9/ I: 28-52.

Labov, W. (1972). Sociolinguistic Patterns. Philadelphia: University of Pennsylvania Press. Lefebvre, A. (I99i). Le français de la région lilloise. Paris: Publications de la Sorbonne.

Long D. and Preston D. (eds) (2002). Handbook of Perceptual Dialectology, vol. 2. Amsterdam: John Benjamins.

Milroy, L. and Gordon, M. (2003). Sociolinguistics: Method and Interpretation. Oxford: Blackwell.

Montgomery, C. (2005). Attitudes to northern English dialects: perception and placement of dialects in the North. Paper presented at UK Language Variation and Change, 5: University of Aberdeen, I2-I4 September.

Niedzielski, N. and Preston, D. (2000). Folk Linguistics. Berlin: Mouton de Gruyter.

Paltridge, J. and Giles, H. (I984). Attitudes towards speakers of regional accents of French: effects of regionality, age and sex of listeners. Linguistische Berichte, 90: 7I -85 .

Pooley, T. (2000). Sociolinguistics, regional varieties of French and regional languages in France. Journal of French Language Studies, I0: I I7-57. 
Pooley, T. (2005). Review of: A. von Nolcken, Einsprachige Mehrsprachigkeit. Sprachwissen und Sprachvariation in der Normandie. Journal of French Language Studies, I 5: I IO-I2.

Preston, D. (1989). Perceptual Dialectology. Dordrecht: Foris.

Preston, D. (1996). Whaddayaknow? The modes of folk linguistic awareness. Language Awareness, 5: 40-74 (cited in Preston, 1999b).

Preston D. (ed.) (I999a). Handbook of Perceptual Dialectology, vol. I. Amsterdam: John Benjamins.

Preston, D. (I999b). A language attitude approach to the perception of regional variety. In: D. Preston (ed.), Handbook of Perceptual Dialectology, vol. I. Amsterdam: John Benjamins, pp. 359-73.

Rispail, M. and Moreau, M.-L. (2004). Francique et français: l'identification des accents de part et d'autre des frontières. Glottopol (revue de sociolinguistique en ligne), 4.

Trudgill, P. (1986). Dialects in Contact. Oxford: Blackwell.

Williams, A., Garrett, P. and Coupland, N. (1999). Dialect recognition. In: D. Preston (ed.), Handbook of Perceptual Dialectology, vol. I. Amsterdam: John Benjamins, pp. $345-58$.

Woehrling, C. and Boula de Mareüil, P. (2006). Identification d'accents régionaux en français : perception et catégorisation. Bulletin PFC, 6: 89-I03.

\section{AP PENDIX}

I. The order in which the thirty-two voice samples appeared on the test tape is as follows: OMM Nancy, YWF Rennes, YMM Rennes, OWM Nancy, YMF Nancy, OMF Rennes, OWM Rennes, YWF Nancy, YWM Rennes, OMF Nancy, YWM Nancy, OWF Rennes, YMM Nancy, YMF Rennes, OWF Nancy, OMM Rennes, YWF Rennes, OMM Nancy, YMF Nancy, OWF Rennes, OWM Nancy, YMM Nancy, OWF Nancy, YMF Rennes, OWM Rennes, YMM Rennes, OMF Nancy, YWM Rennes, YWF Nancy, OMF Rennes, YWM Nancy, OMM Rennes.

2. Here is the text of the protocol shown to all participants in the Pays de la Loire perceptual study along with a map of France blank except for the point de repère cities listed below. Underneath is a sample of the first few lines of the response grid informants were asked to complete after each voice.

J'effectue une enquête qui consiste à faire écouter à un échantillon de témoins un enregistrement de 32 extraits, d'une durée de 30 secondes, d'un texte lu par des Français originaires de la moitié nord de la France.

Après chaque extrait, veuillez répondre, en remplissant la case appropriée, aux questions suivantes.

I Pouvez-vous identifier la région d'origine de cette personne?

2 Cette façon de parler évoque-t-elle une ville particulière ou plutôt la campagne?

3 Pouvez-vous identifier cette personne en termes d'origine sociale ou de catégorie socioprofessionnelle?

4 Pouvez-vous indiquer les caractéristiques évoquées par cette façon de parler (ex. beau, laid, correct, accent des banlieues...)? 


\section{Zoë Boughton}

Quelques-unes des villes principales de la moitié nord de la France sont indiquées sur la carte reproduite ci-dessous pour vous servir de points de repère dans vos identifications.

(The ten cities marked on the map were Brest, Nantes, Rennes, Tours, Rouen, Paris, Lille, Nancy, Dijon and Strasbourg.)

\begin{tabular}{llll}
\hline \hline & \multicolumn{2}{c}{ IDENTIFICATION } & APPRÉCIATION \\
\hline Locuteur & I. Région? & 2. Ville? \\
& Campagne? & $\begin{array}{c}\text { 3. Catégorie socio- } \\
\text { professionnelle? }\end{array}$ & $\begin{array}{l}\text { 4. Quels mots (adjectifs, } \\
\text { substantifs) } \\
\text { associez-vous à cette } \\
\text { façon de parler? }\end{array}$ \\
1 & & & \\
2 & & & \\
3 & & & \\
\hline \hline
\end{tabular}

